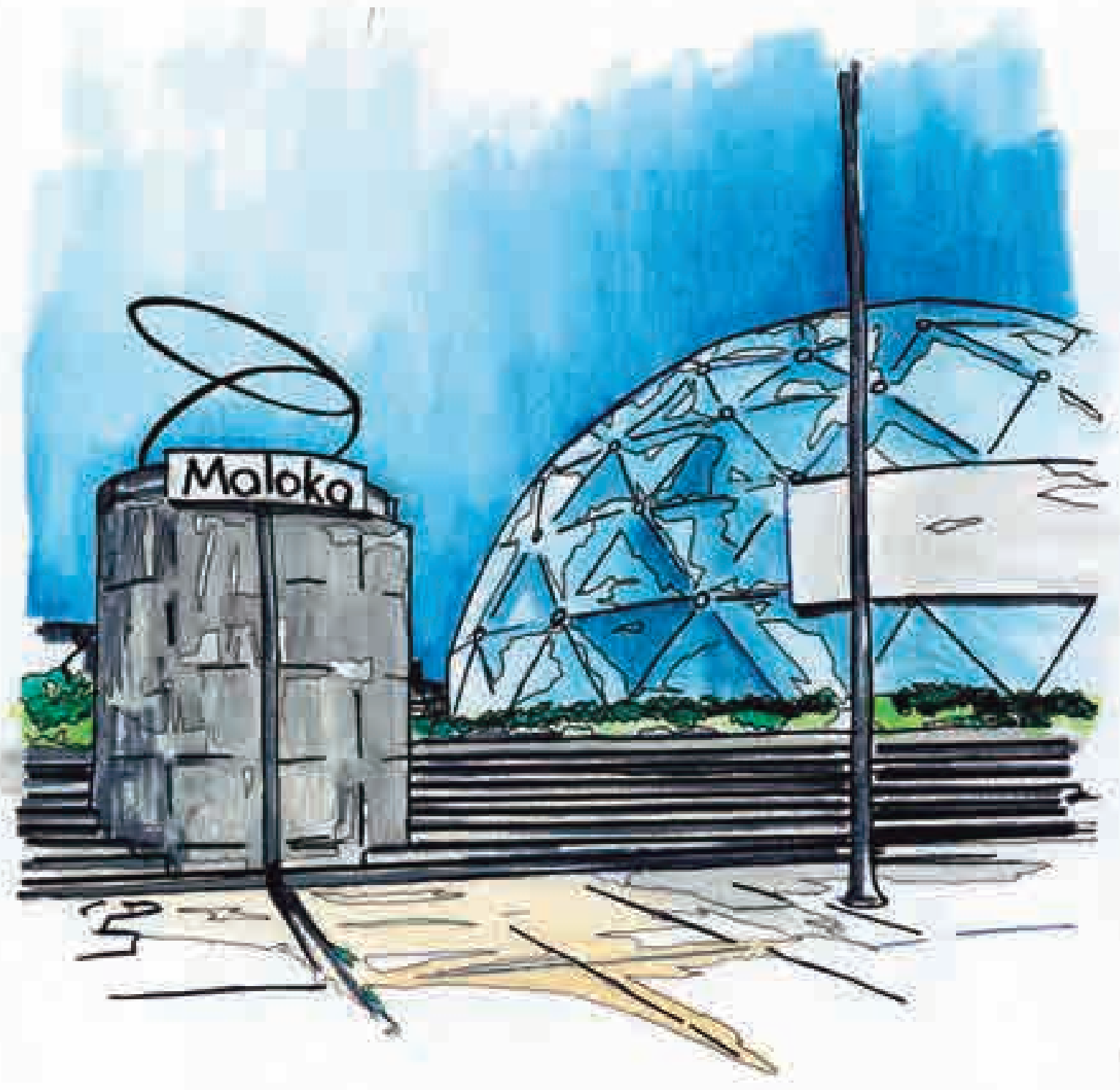

Ilustración 8. Luis Eduardo sintió un vacío helado en los riñones, la desesperanza lo abrigó todo el día, pero no le comentó a nadie. En la noche, en su lecho, antes de cerrar los ojos, balbuceó: —_Estamos muy lejos. La escuela no responde a las necesidades que demanda el país! Al día siguiente se reunió con Javier. 


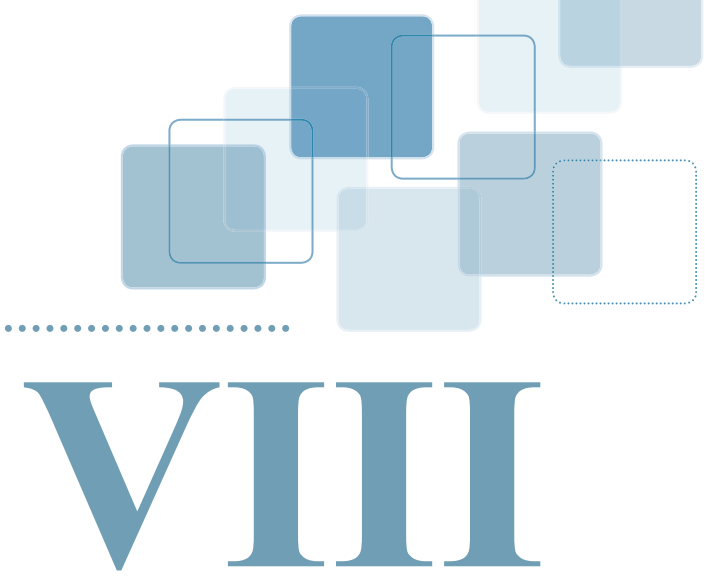

\section{EL CAUDAL DEL RÍO TÁMESIS}

En Inglaterra, Rubén Darío y Carlos Ariel visitaron Cambridge, Londres, Bristol entre otras ciudades. A Rubén lo maravilló el río Támesis, su caudal lo trasladó en el tiempo, recordó, entonces, sus días de joven entusiasta cuando dejó atrás su natal Sonsón para radicarse en la capital del departamento de Antioquia. El Támesis le hizo evocar sus caminatas por el río Medellín, -en aquel tiempo no tenía ni idea de lo que iba a hacer con mi vida- pensó mientras se perdía en las páginas del texto de Paula Sibilia.

Entre tanto, en el colegio Santo Tomás de Aquino, Luis Eduardo sorteaba con singular maestría algunas situaciones cotidianas de la vida escolar y orientaba a los coinvestigadores en la pesquisa de los relatos autobiográficos. Un día encontró en su oficina una resolución para la suspensión de un estudiante indisciplinado, en la parte superior de esta, sujetado con un gancho, vio un pos-it en el que había una nota escrita: "Padre, falta solo su firma. La familia hizo sus descargos. Atte. Javier". Luis Eduardo sintió un vacío helado en los riñones, la desesperanza lo abrigó todo el día pero no le comentó a nadie. En la noche, en su lecho, antes de cerrar los ojos, balbuceó: — ¡Estamos muy lejos. La escuela no responde a las necesidades que demanda el país! Al día siguiente se reunió con Javier. 
-Padre es el caso del estudiante que interrumpe con frecuencia las clases, saca su teléfono móvil, no presta atención y matonea a sus compañeros. Solo falta su firma —dijo Javier, luego de un lacónico saludo.

- ¡No, firmo!

- Padre, el doctor Daza, abogado de la institución, revisó el debido proceso y los descargos de la familia -insistió Javier.

—Javier, ¡No, firmo! —enfatizó Luis Eduardo.

— ¿Por qué, Padre?

- Javier, el Santo Tomás es una escuela, no un juzgado, ni una correccional. No somos jueces sino maestros. ¿Cómo así que descargos? ¿Debido proceso? ¿Cuál fue la estrategia pedagógica que empleamos para prevenir y corregir las dificultades disciplinarias del muchacho?

-Padre, lo cambiamos de curso.

—Eso no es ninguna estrategia. Por favor cite para mañana a la familia del estudiante.

—Padre, la familia y el joven están esperando en mi oficina.

— ¡Mejor! Envíelos a mi oficina. Javier con rostro de desconsuelo abandonó el recinto. Tiempo después Luis Eduardo, la familia y el menor estaban frente a frente. Después de una dura reprimenda verbal, sobre la importancia del respeto, la responsabilidad y el compromiso familiar, el fraile rompió ante los ojos de los padres y del menor, la resolución sancionatoria. La familia salió de la oficina del cura, habían quedado en shock.

Los días pasaron. Carlos Ariel y Rubén Darío regresaron de su viaje y lentamente asumieron sus labores. Luis Eduardo los puso al tanto de los acontecimientos, los coinvestigadores habían realizado a cabalidad la misión encomendada. Días después se encontraron con ellos en la 
Sala de Juntas. Rubén instaló la sesión, agradeció a los coinvestigadores la puntualidad y conminó a Lina para que diera cuenta de sus hallazgos narrativos.

-Buenos días para todos — dijo la mujer con acento paisa. Sin preámbulo abrió un archivo de Word, lo proyectó a través del vídeo beam y leyó el relato de David, estudiante de Quinto grado:

Los sábados: me levanto, desayuno, veo televisión, hago tareas, almuerzo, leo un poco (periódicos, revistas, libros, etc.-), veo televisión, le oro a Dios y me acuesto a dormir. Los domingos: me levanto, desayuno, voy a misa con mis padres, me voy a ciclovía, llego y almuerzo, leo un poco (periódicos, revistas, libros, etc.).Veo televisión, le oro a Dios y me acuesto a dormir. A veces los fines de semana salgo con mis padres a realizar vueltas.

¡Cómo pueden ver, para este muchachito no existen más días que el sábado y el domingo! - agregó la mujer arrancando profundas risotadas. Luego, leyó el relato de Martín, de Segundo grado:

Una vez llego del colegio, lo primero que hago es tomar los alimentos. Luego me quito el uniforme y me coloco ropa formal; reviso las tareas que hay para el día siguiente; realizo las tareas; alisto los útiles y uniformes para la jornada siguiente; no todos los días arreglo mi habitación; después de cumplir las tareas anteriores, juego con mi primo un rato antes de ir a dormir. Por lo general, me quedo en la casa, jugando, apoyo a mi mamá con el aseo del apartamento, juego con mi primo menor, acompaño a mis abuelitos. De vez en cuando salgo a los centros comerciales a divertirme y comer. De vez en cuando voy a la finca con mis papás.

Después la profesora hizo una pausa, pasó revista por el lugar, ¿será verdad tanta belleza? — dijo.

-Analicemos los relatos anteriores -dijo Carlos Ariel.

-Padre, creo que hay una diferencia profunda entre lo que escribe el primero con lo que dice el segundo estudiante —dijo Tulio. Este es más 
dedicado, estudioso, colabora con los quehaceres de la casa, mientras aquel, aunque lee, es más el tiempo que le dedica al ocio.

-Creo que en el caso de David hay algo muy importante - intervino Patricia. Lee revistas, periódicos, libros ¿Acaso no nos quejamos los maestros que nuestros estudiantes no leen? En su relato, David manifiesta en dos ocasiones que ve televisión, pero además hace tareas $\mathrm{y}$, algunas veces, hace vueltas con sus papás. Lo anterior, me lleva a creer que la televisión desempeña un papel muy importante, en la forma como este estudiante construye su relación con el mundo. Además, cuando afirma "A veces los fines de semana salgo con mis padres a realizar vueltas", creo que lo que está manifestando es la apropiación de los entornos urbanos.

-A mí me llamó la atención el segundo relato — dijo Armando. Creo que Martín cuando dice: "no todos los días arreglo mi habitación" está haciendo una sentencia cotidiana. No es habitual ni rutinario, para este niño, el arreglo del lugar donde duerme, para él este ejercicio es cotidiano. Lo cotidiano no es, como ya está claro, lo rutinario. Repite en tres ocasiones que hace sus tareas y dos veces habla de jugar. Esto me lleva a pensar que los estudiantes a esta edad todavía cumplen con sus responsabilidades académicas. En cuanto a lo que juega, me surge la siguiente pregunta ¿Qué juega?

-Pero hay algo que no estamos viendo en ambos relatos —interpeló Nelson. Existe una manifestación cotidiana en la que coinciden David y Martín, el primero dice: "A veces los fines de semana salgo con mis padres a realizar vueltas" mientras que el segundo afirma: "De vez en cuando salgo a los centros comerciales a divertirme y comer". Estas afirmaciones están determinadas por dos adverbios de frecuencia "A veces" y "De vez en cuando" que no revelan con exactitud, cuándo y cuántas veces los estudiantes realizan tales acciones. Sin embargo, aunque no sepamos cuantas veces al mes David hace vueltas con sus padres, ni conozcamos la periodicidad con la que Martín sale a los centros comerciales, lo cierto es que lo hacen. Con lo anterior, quiero 
decir que ir a los centros comerciales y la apropiación de otros entornos urbanos -en el caso de David- es algo cotidiano. De esta manera, el centro comercial, la calle y la ciudad son espacios muy cotidianos en la vida de estos jóvenes.

- Mi trabajo fue con los estudiantes de Sexto grado — dijo Dilia, leyendo los relatos que previamente había seleccionado, los cuales aparecieron ante los ojos de los asistentes en el recinto.

Yo salgo a las 3:00 p.m. y cojo la ruta que me lleva a mi casa, a las 3:45 llego a mi casa y almuerzo, después veo televisión hasta las cinco y comienzo a hacer tareas hasta que las termino, después, a veces si me queda tiempo, me conecto o juego en mi Xbox 360 hasta que llega mi papá, después acompaño a mi papá a cenar, luego alisto maleta, veo un poco de televisión y me duermo. Los viernes salgo del colegio, llego a mi casa, almuerzo, me cambio y salgo con mis amigos hasta las 8:30, me entro y juego Xbox hasta las 9:30 después veo televisión y me duermo como a las 10: 30. Sábado: me levanto, juego en el Xbox 360 hasta que mis papás hagan el desayuno, desayuno, veo televisión como hasta las 10.30 a.m., me baño, me cambio, organizo cuarto, almuerzo y después salgo con mis amigos hasta las 7:30 p.m., después me entro ceno y veo televisión con mis papás y me duermo. Algunas veces, por la tarde salgo con mis papás a caminar y a comer helado. Domingo: me levanto juego Xbox 360, desayuno, hago tareas hasta medio día o más, me baño, me cambio, organizo cuarto, almuerzo y salgo con mis amigos hasta las 7:30, veo televisión, alisto maleta y me duermo (Daniel, Sexto grado).

La narración anterior se realizó en dos momentos: durante la semana y en el fin de semana —agregó la mujer tomando un poco de aire. En ella se puede evidenciar lo que hace Daniel después de clases, en su vida extraescolar. Así, tenemos que después de clases, él realiza sus tareas, ve televisión y juega Xbox 360, como las actividades más representativas. Los viernes después de llegar a casa, comer y cambiarse, Daniel sale 
con sus amigos y vuelve a las 8:30 p.m. Aunque no aclara a dónde va con sus amigos, uno puede suponer que el lugar visitado puede ser un parque, un centro comercial o la calle. De todas maneras, son espacios urbanos. Además, vuelve a enfatizar en ver televisión y jugar Xbox. El día sábado, Daniel dice:

“juego en el Xbox 360 hasta que mis papás hagan el desayuno. Desayuno, veo televisión como hasta las 10.30 a.m., me baño, me cambio, organizo el cuarto, almuerzo y después salgo con mis amigos hasta las 7:30, después me entro, ceno y veo televisión con mis papás y me duermo".

Podemos ver cómo la compañía de sus amigos es muy importante para Daniel, el tiempo que comparten es amplio, pero no revela cuáles son los sitios visitados. El día domingo, "algunas veces" -adverbio de frecuencia como anotaba Nelson hace un rato-, nos revela la existencia de dos lugares cotidianos: la heladería y la calle. Esta última está representada en la expresión "salgo con mis papás a caminar". La televisión y su juego favorito completan la jornada. Dilia hizo una pausa prolongada y constató que ninguno de los asistentes tenía nada diferente que decir. Se sintió complacida y continuó leyendo:

Suena el timbre de salida y me dirijo hacia el parqueadero donde quedan las rutas y empieza el recorrido, soy el segundo que dejan, llego a mi casa, me cambio, me como las onces, descanso un rato, después empiezo a ver el horario y las tareas, habiendo acabado las tareas, si me queda tiempo, juego PlayStation hasta las 8:30 p.m., después veo un poco de televisión hasta las 10:00 p.m. Los fines de semana, me levanto a veces a las 10:00 a.m., me baño, desayuno, me pongo a ayudar a mi mamá a hacer los oficios de la casa, después me pongo a hacer las tareas que tengo, después almuerzo, después me voy a el parque a encontrarme con mis amigos, llego hacia las 6:00 p.m., me pongo a jugar PlayStation hasta las 12:00 o 1:00 a.m. Y el domingo, me levanto a la misma hora que los sábados, me baño, desayuno y me voy al parque, y regreso hacia las 12:00 p.m., descanso un poco, después almuerzo 
y me pongo a terminar lo que me falte o a descansar y me acuesto tipo 10:00 u 11:00 p.m. (Juan Sebastián, Sexto grado).

Este escrito lo divido en dos momentos -como el anterior-: Juan Sebastián deja ver su pasión por su videojuego y por sus visitas al parque. Describe con mucho cuidado lo que hace durante la semana y el fin de semana, sobresalen también sus tareas, su rutina de alimentos y aseo personal. El siguiente relato -prosiguió-:

Los viernes llego al colegio faltando 10 para las 7:00. Voy al locker a sacar los libros de las tres primeras horas, entro a clase, me adelanto si quedé atrasado, hago el trabajo de la clase, después paso a un bloque de ciencias, copio lo que me toque y hago el trabajo, después salgo a descanso, juego fútbol, básquet o ping pong, como mis onces, entro a Educación Física, juego básquet o fútbol, después entro a matemáticas, pongo atención a la profe Andrea, si nos deja una actividad la hago, después voy a Inglés, entramos al laboratorio, jugamos en los computadores, después salgo a descanso, juego hasta la 1:30, voy almuerzo, después juego lo que quede de descanso, entro a Sociales, pongo atención a clase, salgo a Escuelas Deportivas a entrenar básquet hasta las 5:00, voy a mi casa, veo 15 minutos de tele, después juego en el compu, después escucho música mientras cateo en Facebook, juego PES. El sábado me la paso en Facebook, juego en PES y veo tele, por la noche me quedo hasta las 2:00 jugando PES con mi hermano y, el domingo por la mañana, si puedo, voy al parque o a la ciclovía con mi familia, y por la tarde salgo a almorzar afuera de Bogotá y llego a ver tele, juego algo y me acuesto a dormir (Juan Camilo, Sexto grado).

Después de leer el relato de Juan Camilo, Dilia pasó revista por el recinto y se dispuso a realizar el siguiente análisis: El estudiante escribe con especial detalle lo que hace en el colegio, en el aula y por fuera de ella. Es interesante que Juan Camilo diga "juego fútbol, básquet o ping pong" porque aunque es habitual para él la actividad física, no 
siempre practica el mismo deporte. Es decir, jugar fútbol baloncesto o ping pong, siempre que no sea rutinario, se convierte en algo cotidiano para la vida de este niño. En su casa, Juan Camilo escucha música, mira televisión, juega en el computador y su vídeo, juego favorito, y chatea en Facebook. Además, dice Juan Camilo "si puedo voy al parque o a la ciclovía con mi familia”, lo que quiere decir, que el parque y la ciclovía son acontecimientos cotidianos en la vida de esta familia.

En conclusión -hizo una inflexión y continuó-, la frecuencia con la que estos estudiantes visitan algunos lugares determina si son cotidianos o rutinarios. De la misma manera, la periodicidad con la que realizan ciertas actividades también define si son nuevas, únicas o repetitivas.

-Yo trabajé con algunos estudiantes de Séptimo grado - dijo Andrea. Estos son los relatos más significativos:

Salgo de clase y me dirijo a la ruta, mientras llego a mi casa y saludo a mi mamá, luego almuerzo, termino y me dirijo a mi cuarto, prendo mi PC y entro a LOL (League of Leyends) juego on line, también entro a Skype que se llama "Los Gomers del Santoto" donde está Garzón, Machuca, Gómez de 10, ya pronto agregaré a Galindo, abro una partida en LOL cuando ya todos estamos conectados, hablamos por Skype, haber quien tiene tareas, los que tengan no juegan la primera partida mientras las hacen ya que cada partida puede durar una hora. Cuando todos estamos conectados jugamos hasta las 8:00 p.m. y los viernes hasta las 3:00 a.m. o más, ya que al otro día no madrugamos; un día normal me acuesto a las 8:00 o a las 8:30 p.m.

En un fin de semana, algunas veces mi papá me llama para ir al club, nos vemos a las 6:30 a.m., desayunamos y luego nadamos, jugamos golf y tenis, a las 2:30 p.m. almorzamos y continuamos, a las 6:30 p.m. quedo rendido y él me deja en la casa, apenas llego juego LOL con los de mi grupo, a las 8:30 p.m. la comida, y juego hasta tarde, y algunas veces salgo a comer helado con mi 
hermano, mi hermana y mi mamá, a eso de las 12:00 o 1:00 a.m. me acuesto (Wilson Daniel, Séptimo grado).

Andrea continuó sin pausa alguna.

Después de salir del colegio me dirijo a coger un bus, el cual me lleva a mi casa. Al llegar siempre está mi mamá, almuerzo, en este espacio le cuento como fue el día en el colegio, luego descanso un poco viendo televisión, o escuchando radio, luego voy a hacer tareas y al terminar, si no tengo que salir con mi mamá a hacer vueltas, voy a sentarme a jugar videojuegos. En la noche alisto maleta y el uniforme, después de esto voy a comer algo y veo televisión un rato antes de dormir a las 9:00 p.m. En el sábado aprovecho para levantarme tarde, desayunar y ver televisión un rato en la mañana, luego me siento a hacer las tareas en el poco rato que me queda en la mañana y después del almuerzo me siento toda la tarde que sea necesaria para terminar las tareas. En la noche veo televisión hasta que me da sueño y me voy a dormir. En el domingo me levanto tarde como el sábado, desayuno y veo televisión hasta que mi papá me llame para decirme a qué horas me recoge. Luego, me arreglo y lo espero jugando videojuegos o viendo televisión, cuando me recoge salimos a lugares distintos y la pasamos juntos. En la tarde (entre 5:00 a 6:00 p.m.) mi papá me deja en mi casa y se va, luego como algo, hago la maleta del lunes y el uniforme, y veo televisión con mi mamá hasta aproximadamente las 9:30 (Oscar, Séptimo grado).

Andrea, se detuvo un momento, hizo una pausa profunda y continuó.

Subo a la ruta para llegar a mi casa, espero 45 minutos hasta llegar. Después de llegar me cambio el uniforme, descanso 10 minutos y empiezo a hacer tareas, bien sea en el cuaderno o en el computador, alisto maleta para el día siguiente, molesto con mi papá un rato o lo acompaño a hacer sus vueltas, luego ingreso a Internet y busco videos que causen risa y, por último, me meto al Facebook al grupo de tareas de 701 para colaborarle a otras personas que 
desean saber de tareas para el día siguiente, después de todo esto llega mi mamá y le cuento todo lo que pasó en el día. Durante el fin de semana, el sábado me levanto a las 6:30 a.m. para desayunar y hablar con mi prima de Estados Unidos, ya que ella se va a hacer ejercicio, espero que llegue mi papá de trabajar para ir a jugar ping-pong y basquetbol. El domingo reviso todo lo que pasó en la semana para hacer todo y me conecto al computador y publico lo de la semana en el grupo de tareas y me acuesto a dormir (Nicolás, Séptimo grado).

De lo narrado por Wilson, sobresale la importancia que representa para los jóvenes de hoy estar conectados, jugar on line colectivamentedijo Andrea. Lo hacen desde temprano hasta bien entrada la madrugada. Ello explica, en buena medida, por qué los estudiantes duermen en algunas clases. Además, la realización de videollamadas, a través de Skype, para indagar si hay tareas o no para el día siguiente es un recurso que los estudiantes de hoy empiezan a utilizar. Cuando Wilson dice: "En un fin de semana algunas veces mi papá me llama para ir al club, nos vemos a las 6:30 a.m., desayunamos y luego nadamos, jugamos golf y tenis", está manifestando que el club es otro sitio cotidiano, pues el adverbio de frecuencia "algunas veces", así lo sugiere. Nadar, jugar golf o tenis también son acontecimientos cotidianos para Wilson, pues "algunas veces" lo hace. Además, aparece la heladería como espacio cotidiano, lo cual se evidencia cuando Wilson afirma "algunas veces salgo a comer helado con mi hermano, mi hermana y mi mamá”.

El relato de Oscar está en la misma dirección del anterior. Oscar dice: "si no tengo que salir con mi mamá a hacer vueltas voy a sentarme a jugar videojuegos". Salir a "hacer vueltas" quiere decir que estas se hacen en la ciudad, entonces, la calle aparece ante los ojos de quienes las hacen. La calle toma una significación diferente cuando se "hacen vueltas" que cuando se sale a otra cosa diferente. La calle es otro escenario cotidiano que rodea la vida de nuestros jóvenes — reafirmó la mujer. Las narraciones de Oscar y Wilson también dejan ver que ambos viven con sus madres. Los padres, en ambos casos, no conviven con sus 
hijos y solo comparten el fin de semana con ellos. La televisión y los videojuegos se hacen muy notorios en ambos casos.

El último relato encuentra relación con los dos anteriores. Nicolás, afirma: "molesto con mi papá un rato o lo acompaño a hacer sus vueltas", ello me lleva a pensar que "hacer vueltas" además de ser algo cotidiano, porque ni Wilson ni Oscar ni Nicolás las hacen todos los días, o van siempre a los mismos lugares con sus padres, hablan y se expresan con identidad juvenil frente a ciertas actividades, por ejemplo "hacer vueltas". Nicolás también manifiesta su interés por el deporte, lo practica, creo yo, en el parque. Este lugar aparece detrás de los juegos de ping pong o baloncesto. Conectarse es de la misma manera muy importante para él. Por último, Nicolás revela la existencia de un grupo de Facebook en la que él y sus compañeros se enteran de las tareas que hay por realizar. Facebook e Internet, metáfora del "conectarse" están revalorizados por los jóvenes, es decir, las redes sociales y el ciberespacio son otros dos escenarios cotidianos por donde transita la vida juvenil actual — puntualizó.

Los tres frailes estuvieron muy atentos en cada una de las intervenciones de los coinvestigadores. Sin embargo, el tiempo que habían dispuesto para este ejercicio se había terminado. Rubén Darío agradeció la colaboración que este grupo de maestros les estaban prestando. Quedaron solo los tres. Acto seguido, Luis Eduardo les informó a sus hermanos de Orden que la entrevista con el doctor Antanas Mockus se cumpliría el día de mañana a las dos de la tarde en Corpovisionarios. Había podido ubicar al doctor Mockus, mientras Rubén Darío y Carlos Ariel estaban en Europa, con las coordenadas que Fabián Sanabria les había dado meses atrás. 
